\title{
Editorial
}

\section{Academic Knowledge Production and University Presses: Some Random Thoughts}

Ever since the news about Stanford's University Press having a catastrophic budget cut came out, ${ }^{1} \mathrm{I}$ have been contemplating scholarly publishing and its purpose. Perhaps this is because the "crisis" around university presses ${ }^{2}$ is very similar to the rhetoric that has surrounded academic libraries since web browsers hit higher education - rhetoric that at any one time has both utopian and apocalyptic threads. As a journal editor, my interest in scholarly publishing is more than passing, although as much as I am committed to these efforts, it is not the livelihood for me that librarianship is and, as such, my stake in publishing is not a question of survival. However, as a steward of a scholarly journal, as an author of professional publications, and as an educator of information literacy and scholarly methods, I do have some thoughts I would like to share about what is happening with university presses, the impact on higher education, and on knowledge dissemination.

The climate around higher education is having an impact on every aspect of knowledge production. While there are those who may point to certain data ${ }^{3}$ to decry any concerns about a mass extinction of presses, it seems to me that what we are witnessing is not so dissimilar to what is happening with institutions of higher education - where smaller struggling institutions who have not claimed a niche or maintained a sustainable model may close, elite institutions will pick and choose their priorities (and it seems that the humanities are ever at risk) and state institutions will remain (perhaps in a "too big to fail" model?), albeit changed and in some ways dramatically.

It seems to me that the initial decision to make that cut at Stanford was representative of the conflict between higher education as an altruistic effort - to educate as well as to create and disseminate knowledge-and the economics and social forces at work on institutions of higher education. In spite of this trend, calling the announcement a shock is an understatement-Stanford has a very reputable scholarly press that addresses both traditional and emerging research areas. I know one humanities scholar with a contract with the press who was stunned and is now looking for other viable scholarly venues in the area of research (spoiler: there are not a lot, particularly when considering that commercial scholarly publishers are also scaling back their humanities offerings).

\section{Dynamics Influencing University Presses}

The forces at work on scholarly publishing, even those within the academy, are varied and, in many cases, in conflict. Researchers have long retained the control over their discoveries or creations, as many institutions concede the intellectual property. The traditional model of scholarly publishing struggles to sustain its efforts. The open access movement aligns with the mission of public and land grant universities with an emphasis on transparency and public scholarship. Lastly, the ramping up of technology commercialization initiatives on campuses 
seeks to bring innovations to industry and allow institutions more control over the research that is produced by affiliates. I may be alone in this, but I see some inherent conflicts of interests in these priorities - all involved in a tug-of-war with the knowledge that is produced in universities and colleges.

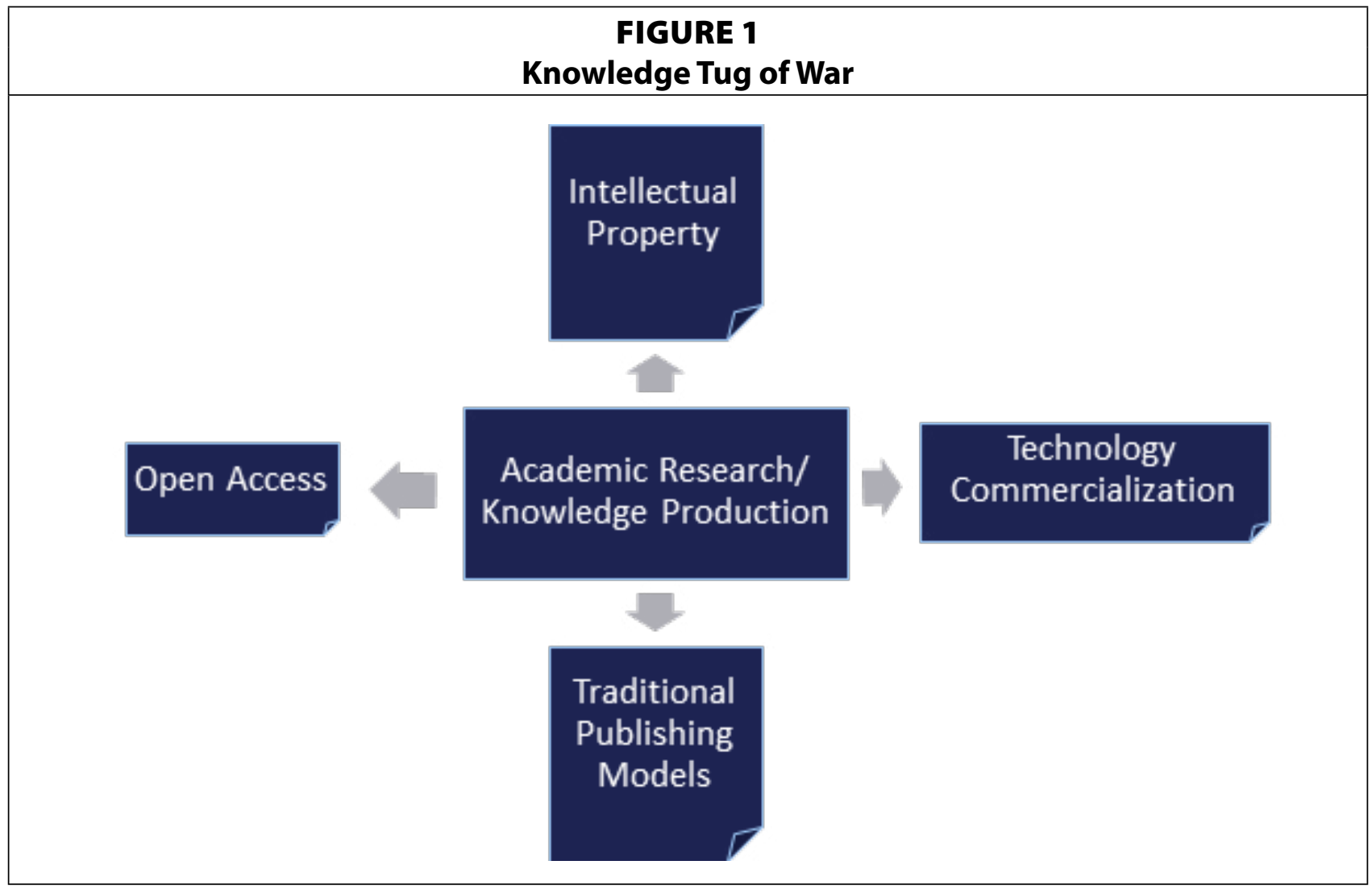

Witnessing this tension as well as the various news stories about university presses (from closures and budget reductions to restructuring where it seems almost commonplace now that the University Press is moving under the library), it prompts me to ask what the purpose of the scholarly press is. Certainly, the distinction between commercial academic presses and university presses is obvious ${ }^{4}$ and for the purposes of this editorial, I will focus on the university press and its inarguable connection to the educational mission. University presses run the gamut from Cambridge, which is touted as the pinnacle of quality (and seems to have adopted a model that is not just sustainable but profitable when one considers all of the electronic offerings) to smaller presses that focus on specialized research and presses that might be called vanity presses (in that they publish a lot of work from their own institution). This last category may be what prompts universities to put the press under the library - as the very model that library repositories have adopted is a self-empowered, self-published model for any affiliated researchers. Given the broad range of options, the question or purpose (or mission) is really the most germane at the institutional level.

So, considering a university press, what is the mission? How does (or should) it align with the larger institutional goals? Most pragmatically, does the press have a service mission (as it might for public or land grant universities)? In other words, is the goal profit, cost-recovery, sustainability, or something more altruistic? This is probably the most important first question 
to ask - one not controlled by the press itself (unless it is already self-sustaining) - but by the parent institution or university.

According to Peter Berkery of the Association of University Presses, some 80 percent of university presses receive subsidies from their affiliated institutions, which on average account for roughly 15 percent of their total budget. Without that additional funding, the presses would have to significantly curtail their operations, and some might even have to shut down. While some university presses engage in wasteful spending, the fundamental reason why most require subsidies is that they are not intended to make a profit. This point brings us back to my first question: What is the point of a university press? Its main task, quite simply, is to publish works that expand our knowledge. Such books do not necessarily attract a large readership. ${ }^{5}$

The Scholarly Kitchen recently published a post from Christine Tulley that enumerated "Emerging Trends in the Academic Publishing Life Cycle:"

- Shift 1: Academics Think Rhetorically (as Writers AND Readers)

- Shift 2: After the Top 2-3 Journals, Rank Matters Less

- Shift 3: Academics View Librarians as Scholarly Research "Partners" vs. Support

- Shift 4: Academics Increasingly Work with Publishers to Promote Content ${ }^{6}$

The last 2 points have ramifications for university presses in that the distance between the press and its stakeholders (content creators, consumers, customers) is decreasing.

So, in thinking about how presses might position themselves - the questions to ask are strategic:

- What is the purpose of a scholarly press? The most obvious is the dissemination of knowledge. But the growing trend that business models have gotten into higher education has impacted even this - the accountability and focus on return on investment has raised the question of whether university presses are worth it. They are not, with very rare exceptions, money makers. They are subsidized efforts for a purpose-so what is the purpose?

- Once the question about mission is answered, a critical follow-up question is, who is the audience? Scholarly publishing has traditionally assumed it to be other scholars (with periodic exception being textbooks or manuals for studies or practitioners). Presses must answer this explicitly for each project they take on (and most presses actually expect it to be addressed in detail in any book proposals). However, it is a question that the press needs to consider more broadly as it positions itself and plans for the future.

To that end, some sort of environmental scan - like a SWOT analysis - would be useful if one has not already been done. Strengths and weaknesses are aspects that the press does have some control over-hiring new expertise or skills, changing organizational structure, introducing new series or formats, etc. The opportunities and threats are largely outside their control-but how they respond to them is completely within it. I would opine that many presses, similar to some libraries, have allowed themselves to be buffeted about on the wind of change while not really taking control or anticipating how to respond to certain situations.

University presses have a unique opportunity to support the research and knowledge that is coming out of the academy with processes that are transparent and standards that are 
rigorous. Consumers of information - whether students and educators, researchers, citizens, practitioners, or decision makers - need to have strong and reliable indicators about what information is credible. University presses are in a position to provide that.

\section{Some Thoughts on "Quality"}

When I think about scholarly publishing, it assumes rigor and objectivity. I am not talking about the nebulous reference to quality or rigor that is an ill-defined, "I'll know it when I see it" assessment. Having credible, vetted information is critical in the information environment - where information is coming in all formats and venues, for all purposes, and from all different kinds of authors and publishers. That perspective that information is published to inform is a naïve one and one that consumers cannot trust.

With grant research, the review is prior to the actual research - and must adhere to the expected standards of the granting agency. A repository may have indications of standards or rigor post publication - usage of datasets that result in publications, mentions in news, citations, etc. Even digital projects may indicate rigor or impact when other institutions sign on to be part of them. Generally, however, scholarly publications derive their quality markers (at least initially) from the venue in which they are published. It may be argued that this quality is then false-and predicated on established titles. However, there are new journals created - and their quality is often marked by the makeup of their editorial board, the rigor (and presumed transparency) of their processes and the resulting published product.

\section{A Model for Positioning Presses}

While I was considering the purpose of a press (at 4 in the morning), I started to look at this question through the lens of Ernest Boyer's scholarship theory (which I have always thought was particularly relevant for academic librarianship as well as higher education more broadly). Boyer provides a model that is very relevant across disciplines (and interdisciplinary):

- The scholarship of discovery - innovation and new knowledge

- The scholarship of integration-interdisciplinary, cross-disciplinary

- The scholarship of application (scholarship of engagement) - extension falls under this but I would also argue that technology commercialization efforts and application within the practice also do

- $\quad$ The scholarship of teaching and learning (scholarship of pedagogy) ${ }^{7}$

It may just be the early hour of my contemplations, but it seemed to me that this model of scholarship was also particularly relevant for scholarly presses and how they might position themselves for the future. There have been numerous studies that have examined Boyer's model in light of scholarly communities, disciplinary scholarship, relevance in the classroom, application for purposes of evaluation and tenure, and so on. Scholarly presses are often, either explicitly or implicitly, included in these discussions.

One of the primary drivers around how a press positions itself should be related to the expertise, research, and products that are generated in the institution. At least, initially looking at the products without any restriction of the audience, mode, format, context, or purpose will provide a more realistic picture of the possibilities. Using Boyer's model as a framework, figure 2 is an idea of how scholarly products might help position the press. 


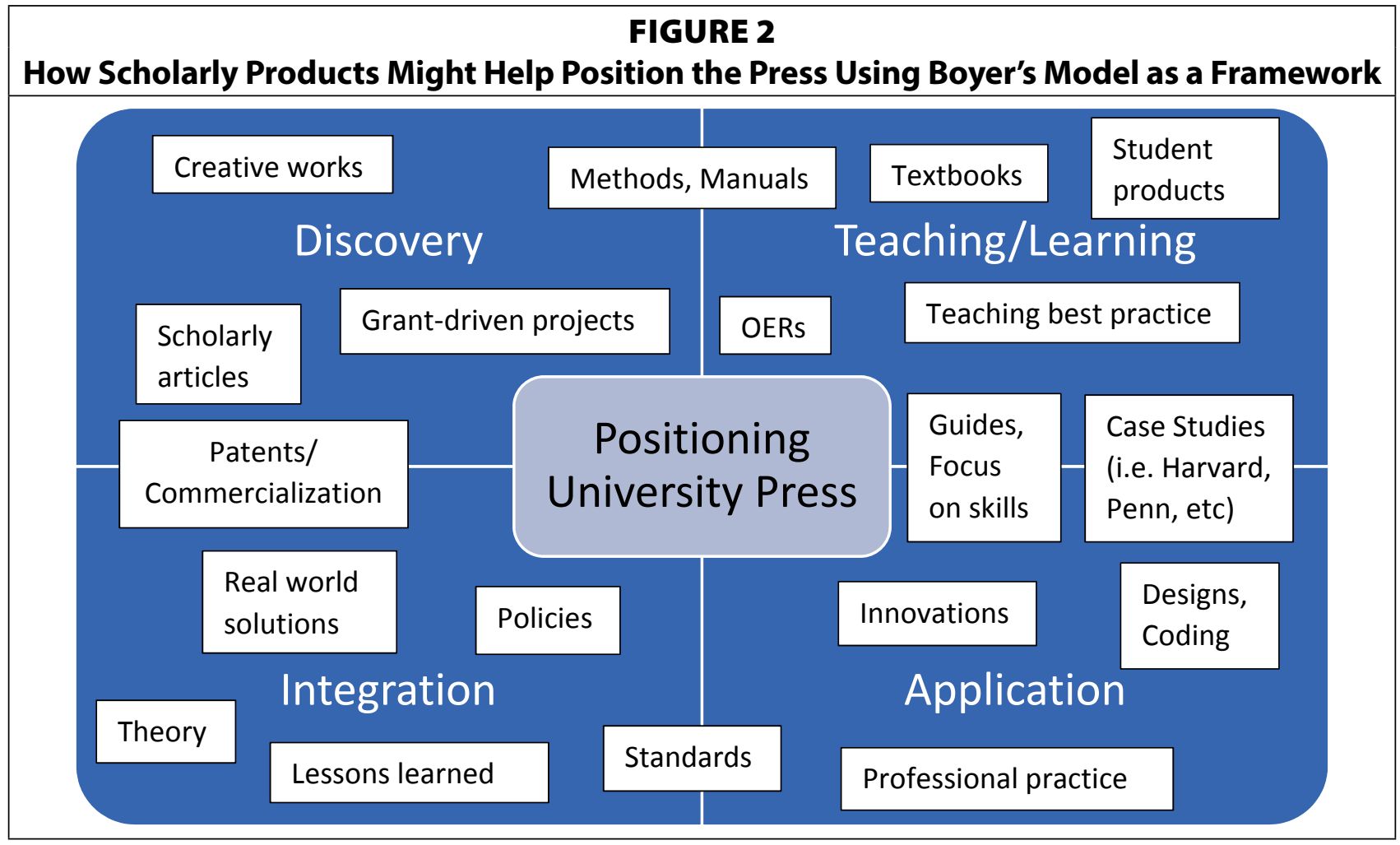

The scholarship of discovery is the most traditional category - new knowledge - but there is an opportunity for presses to engage with "pure" research by supporting nontraditional formats or functions - software programs, creative works, interactive platforms, and graphicsrich products, among them.

Figure 2 is only an example to provide an idea of how Boyer's model might translate to press activity but I believe that it offers a useful way of looking at how presses might "find their space" and their audience. Presses need to differentiate themselves (and some have) instead of maintaining the inertia that has sustained them for years. It is clear to me at least that "the way we have always done it" is the harbinger for either great change or inevitable dissolution.

\section{Collaborating with the Library}

As mentioned previously, there are a number of shifts in institutions of higher education, putting the university press under the library. There is, inarguably, an affinity between the activities of the press and the library, particularly with the widespread initiatives in academic libraries around scholarly communications and repositories.

Institutional scholarly and data repositories are a public service, making academic research available to the public. They make the research of an institution discoverable-for purposes of disseminating knowledge to the public, fostering collaboration (within the institution, more broadly in the discipline, and across disciplines), inviting the application in practice and industry, or promoting the reputation of the scholar, department, or university. However, I would argue that it is a type of self-publication and the objective review for purposes of quality (at least, initially), is minimal. This is where post peer review, commenting, use or replication, and references may provide some indicators of quality. As a librarian working with social science departments, I have always been a fan of ICPSR at University of Michigan-and a few years 
ago, they instituted a facet to their repository that provided a very transparent indicator of quality - cited references of who was using their specific datasets.

An ancillary question related to the treatment of knowledge production in universities is, how do educational records such as theses and dissertations fit into the scholarly publishing of a university? This is a topic that I have touched on before but I wanted to take a moment to clarify. Theses and dissertations are products of the university but they are also scholarly records of the learning process. The standard to which they are held is much different from that which a published scholarly monograph has to meet. Yes, a thesis or dissertation is reviewed by scholars in the field (in the conferring department) but they each use different criteria than a scholarly book or journal - and the reviews are hardly impartial. However for these products of universities to be entered into the review and determination of the quality of the research, it is critical that there be no bias, favoritism, mixed motive, or conflict of interest (including allegiance to the university or politics about departmental standing).

I would assert that University Press Imprints should be kept separate from library identity - at least, if the priority is on a clientele beyond just the institution. It is important to be very clear about how the library (and repository) is distinctive from the university press. Some of the platforms, software, resources, and staffing may be shared, but the audience, mode of delivery, and method of processing (and review) may be very distinct. The integrity of the missions and processes should be kept intact - and must be made transparent.

\section{Other Opportunities for Collaboration}

Provided that the mission of the university press aligns with that of the institution of which it is a part, there are a number of other opportunities that may present themselves.

Just as with repositories, selecting a niche or a scope that plays to the reputation or strengths of the institution is strategic. Following that example, if a scholar has years of political polling data back to Reagan, putting it in an institutional repository may be useful for preservation and discovery. While the institutional repository may make that connection clear, it may be more relevant to put it into a disciplinary or subject repository such as ICSPR or Roper Center, which both have excellent reputations for social science survey data and are where scholars, students, or practitioners looking for polling data will go first. In this way, it will increase the possibility of discovery and use of data as well as the perceived prestige/expertise (which may also be derived from the prestige of their academic programs and faculty). University Presses can also adopt this strategy-leveraging the experts that are at the institution and piggybacking their reputation on the prestige of the top-tier programs.

Related to the scope: collaborate with researchers to enhance the services or expertise of the press. Don't choose what is an already saturated subject area-no one needs another press focusing on political science (and it is unlikely that one could compete with Cambridge or Oxford). Instead identify areas of excellence where there is a strategic advantage. For example, if there is a premiere nautical archaeology program at the institution then talk to that group and gain insight into how they might contribute to the operations, recommend reviewers, or suggest innovations.

Considering partners and interested parties: look beyond academia. In this academic climate, the "beyond" means looking at academia more critically. This scrutiny (and accountability) is influencing higher education in ways that are upsetting paradigms - and institutions are largely slow to react. Critics are often recognized as people and organizations that have 
signaled their investment in higher education, but it is a missed opportunity (and one that can damage an organization) to ignore citizens, government agencies and lawmakers, nonprofit organizations, and other stakeholders.

Lastly (and most pragmatically), determine what the university press can do and do it well. If there is a high level of technical expertise, graphic design, or social media talent, leverage that. If you don't have that (and it can't be effectively grown in house), don't fake it. Just as with academic libraries, a university press is dependent on being credible, reliable, transparent, and maintaining quality standards.

\section{Notes}

1. Grant Barnes, "What Really Happened at Stanford University Press: an Insider's Account," Chronicle of Higher Education, May 10, 2019, https://www.chronicle.com/article/What-Really-Happened-at/246276 [accessed 11 June 2019].

2. Samuel Cohen, "Scholarly Publishing's Last Stand: When university presses close, so do our minds," Chronicle of Higher Education, April 22, 2018, https://www.chronicle.com/article/Scholarly-Publishing-s-Last/243187 [accessed 11 June 2019].

3. Andrew Albanese and Annie Coreno, "University Presses Are Not in Crisis," Publishers Weekly, April 27, 2018, https://www.publishersweekly.com/pw/by-topic/industry-news/libraries/article/76726-university-pressesare-not-in-crisis.html [accessed 11 June 2019].

4. Albert N. Greco and Alana M. Spendley, "The Price of University Press Books, 2012-14," Journal of Scholarly Publishing 47, no. 2 (January 2016): 106-120, https://www.utpjournals.press/doi/abs/10.3138/jsp.47.2.106 [accessed 11 June 2019].

5. Ilya Somin, “University Presses Shouldn't Have to Make a Profit,” The Atlantic, May 11, 2019, https://www. theatlantic.com/ideas/archive/2019/05/why-cuts-stanford-university-press-are-wrong/589219/ [accessed 11 June 2019].

6. Christine Tulley, "Guest Post-Emerging Trends in the Academic Publishing Lifecycle," Scholarly Kitchen, March 27, 2019, https://scholarlykitchen.sspnet.org/2019/03/27/guest-post-emerging-trends-in-the-academicpublishing-lifecycle/ [accessed 11 June 2019].

7. Ernest L. Boyer, Scholarship Reconsidered: Priorities of the Professoriate, Lawrenceville, NJ: Princeton University Press, 1990. 